\title{
Curing characteristics, mechanical properties and morphology of butyl rubber filled with ground tire rubber (GTR)
}

\author{
Krzysztof Formela $\cdot$ Józef T. Haponiuk
}

Received: 24 March 2013/Accepted: 11 December 2013/Published online: 18 January 2014

(C) The Author(s) 2014. This article is published with open access at Springerlink.com

\begin{abstract}
The results on testing application of ground tire rubber (GTR), as potential filler for butyl rubber, are presented. The GTR content variation, within the range of 10-90 phr, was studied with respect to the vulcanization process, static mechanical properties (tensile strength, elongation-at-break, hardness and resilience), dynamic mechanical properties and the morphology of the obtained vulcanizates. Butyl rubber was characterized by its low compatibility to other elastomers [i.e., natural rubber and styrene-butadiene rubber (SBR) - the main ingredients of tires] and low degree of unsaturation. To evaluate the impact of these factors on curing characteristics and mechanical properties of butyl rubber vulcanizates filled with GTR, the same compositions of SBR compounds, cured under identical conditions, were used as reference samples. Based on the obtained data, it can be stated that butyl rubber vulcanizates containing $30 \mathrm{phr}$ of GTR as filler revealed the highest tensile strength and elongationat-break. The microstructural analysis of a sample containing $30 \mathrm{phr}$ of GTR revealed strong interactions between the butyl rubber matrix and GTR. This phenomenon resulted mainly from two factors. First, the cross-link density of the butyl rubber matrix was affected by its competition against GTR for cross-linking agents. Secondly, the migration of carbon black particles from GTR into the butyl rubber matrix had a significant impact on properties of the obtained vulcanizates.
\end{abstract}

Keywords Recycling - Waste rubber - Elastomer blends . Butyl rubber · Filler

K. Formela $(\bowtie) \cdot$ J. T. Haponiuk

Department of Polymer Technology, Faculty of Chemistry,

Gdansk University of Technology, 80-233 Gdansk, Poland

e-mail: kformela.ktp@gmail.com

\section{Introduction}

There are numerous research works which have attempted to design novel methods of resolving the recycling problem of scrap rubbers and to achieve alternative products based on recycled polymeric materials. The studies in this area have focused mainly on searching new methods of material recycling and on improving the existing methods. The main developed trends in material recycling of scrap rubber, specially reused tires, involve size reduction of scrap rubber and using of obtained products as fillers in polymeric compositions and bitumens [1-3] or as substrate in pyrolysis $[4,5]$ and devulcanization processes $[6,7]$. The economic and environmental factors related to the reduction of energy and materials costs for manufacturing of new products recommend a direct application of ground tire rubber (GTR). This is the most justifiable way because in this case GTR does not require any additional processing, for it compensates the production cost of novel materials. Ground tire rubber has been mainly used as filler in polymer compositions [8-11], thermoplastic elastomers [1215] and also as modifier of bitumen [16-18] and cements [19].

Products obtained from the material recycling of reused tires, i.e., reclaimed rubber and GTR are commonly applied in rubber industry as rubber substitute and inactive fillers for rubber blends. However, the published studies focus mainly on rubber compounds based on natural rubber [2022] or styrene-butadiene rubber (SBR) [23, 24]. Ground tire rubber/carbon black mixture as hybrid filler for natural rubber has been investigated recently [25], indicating that the partial replacement of active filler, i.e., carbon black with GTR has a favorable influence on the mechanical properties and processing potential of the prepared vulcanizates. In research works [26, 27], GTR was used as semi- 
active filler of SBR. The authors stated that the addition of up to $50 \mathrm{phr}$ of GTR only slightly affects tensile strength and tear strength of the tested blends. The mechanical properties of obtained rubber compounds may be also increased by devulcanization [28] or chemical modification [29, 30] of GTR.

Applications of GTR as filler in other commonly used rubbers such as nitrile rubber, butyl rubber, ethylene-propylene-diene rubber, etc. are presented only in a few works, including investigation on waste rubber as potential filler for nitrile rubber [31] and compatibility improvement of obtained rubber compounds via surface modification of GTR with plasma [32]. In a research work [33], the variable content of ultrasonic devulcanized butyl rubber obtained from tire-curing bladder has been studied with respect to the mechanical properties of butyl rubber vulcanizes. Earlier research work on usage of GTR in polymeric compositions [34] suggested that low polarity and decrease in degree of crystallinity of polymeric matrix influences interphase compatibilization in the obtained products positively.

In the present work, the correlation between GTR content and properties of vulcanizates based on butyl rubber were investigated. The solubility parameter for butyl rubber was $15.9 \mathrm{MPa}^{1 / 2}$. Ground tire rubber was primarily a combination of SBR $\left(\delta=17.5 \mathrm{MPa}^{1 / 2}\right)$ and natural rubber $\left(\delta=16.8 \mathrm{MPa}^{1 / 2}\right.$ ) [35]. Comparing the solubility parameters of GTR and butyl rubber, it may be expected that the components are not compatible. To estimate the influence of low compatibility and low unsaturation degree of butyl rubber on curing characteristics and mechanical properties of butyl rubber vulcanizates filled with GTR, the same compositions of SBR (solubility parameter closer to solubility parameter of GTR) vulcanized compounds were used as reference samples under identical conditions.

\section{Experimental}

\section{Materials}

Ground tire rubber (mix of passenger and truck tires in ratio of 50:50) from scrap tires (1.5 mm fraction) was obtained by grinding at ambient temperature. Ground Tire Rubber was obtained from ABC Recykling, Krosno Odrzanskie (Poland). The characteristics of GTR are presented in Table 1.

Lanxess Butyl 402 (IIR) (Mooney viscosity: $33 \pm 4 \mathrm{ML}$ $(1+8), \quad 125{ }^{\circ} \mathrm{C}$; unsaturation: $\left.2.25 \pm 0.20 \%\right)$ was obtained from Lanxess Rubber N.V. (Belgium).

KER 1502 SBR (Mooney viscosity: 46-54 ML (1 + 4), $100{ }^{\circ} \mathrm{C}$; chemically bound styrene content: $23.5 \%$ ) was obtained from Synthos Group, Oswiecim (Poland).
Table 1 Specifications of ground tire rubber

\begin{tabular}{lll}
\hline Properties & Mass content $(\%)$ & Method \\
\hline Acetone extract & 8.7 & PN-92/C04219 \\
Rubber additives & 15.3 & TGA \\
Rubber (SBR, NR) & 48.7 & TGA \\
Carbon black & 32.7 & TGA \\
\hline
\end{tabular}

Toluene for analysis work and the curing agents for vulcanization were purchased from POCH S.A. and Standard Sp. z o.o. (Poland).

\section{Sample preparation}

Rubber compounds based on butyl rubber filled with GTR (Table 2 for the GTR composition) were obtained using a Buzuluk laboratory mill. The following mill settings were used: friction equaled 1.08 and the gap width varied between 1 and $8 \mathrm{~mm}$. The sequence of material addition on two-roll mill was according to the order presented in Table 2. First, butyl rubber and GTR blends were masticated. In the next step, vulcanization accelerators were added. Sulfur was introduced at the end of mixing. The total mixing time was around $30 \mathrm{~min}$.

The obtained rubber compounds were vulcanized according to the estimated optimal time at $160{ }^{\circ} \mathrm{C}$ under a pressure of 4.9 MPa. The same compositions of SBR vulcanizates cured under identical conditions were used as reference samples.

\section{Measurements}

Swelling test was carried out by estimation of the swelling degree in toluene at room temperature. Each sample of around $1 \mathrm{~g}$ weight was initially weighed on an electronic balance with the accuracy of $0.0001 \mathrm{~g}$. The samples were then immersed in toluene to reach an equilibrium swelling state and weighed again. The swelling degree was calculated according to Eq. 1:

$Q=\frac{m_{t}-m_{0}}{m_{0}} \times \frac{\rho_{\mathrm{p}}}{\rho_{\mathrm{s}}}$

where $Q$ is swelling degree, $m_{t}$ is mass of sample swelled for time $t(\mathrm{~g}), m_{0}$ is mass of dry sample $(\mathrm{g}), \rho_{\mathrm{s}}$ is density of sample $\left(\mathrm{g} / \mathrm{cm}^{3}\right)$, and $\rho_{\mathrm{p}}$ is density of toluene $\left(\mathrm{g} / \mathrm{cm}^{3}\right)$.

The vulcanization process was investigated at $160{ }^{\circ} \mathrm{C}$ in accordance with the ISO 3417 standard. The measurements were performed with a Monsanto R100S oscillating disc rheometer (USA). The rotor oscillation angle was set at $3^{\circ}$, while the torque range varied from 0 to $100 \mathrm{dNm}$. Tensile strength and elongation-at-break of the obtained vulcanizates were determined with a Zwick Z020 testing machine 
Table 2 Composition of tested compounds

\begin{tabular}{|c|c|c|c|c|c|c|c|c|c|c|}
\hline \multirow[t]{2}{*}{ Component (phr) } & \multicolumn{10}{|c|}{ Sample } \\
\hline & B0 & B1 & B2 & B3 & B4 & B5 & B6 & B7 & B8 & B9 \\
\hline IIR & 100 & 100 & 100 & 100 & 100 & 100 & 100 & 100 & 100 & 100 \\
\hline GTR & - & 10 & 20 & 30 & 40 & 50 & 60 & 70 & 80 & 90 \\
\hline Zinc oxide & 5 & 5 & 5 & 5 & 5 & 5 & 5 & 5 & 5 & 5 \\
\hline Stearic acid & 3 & 3 & 3 & 3 & 3 & 3 & 3 & 3 & 3 & 3 \\
\hline MBT* $^{*}$ & 0.65 & 0.65 & 0.65 & 0.65 & 0.65 & 0.65 & 0.65 & 0.65 & 0.65 & 0.65 \\
\hline TMTD** & 1.3 & 1.3 & 1.3 & 1.3 & 1.3 & 1.3 & 1.3 & 1.3 & 1.3 & 1.3 \\
\hline Sulfur & 2 & 2 & 2 & 2 & 2 & 2 & 2 & 2 & 2 & 2 \\
\hline
\end{tabular}

* MBT 2-mercaptobenzothiazole, ** TMTD tetramethylthiuramdisulfide

(Germany) in accordance with the ISO 37 standard. Crosshead speed was $500 \mathrm{~mm} / \mathrm{min}$. Shore hardness was measured with a Zwick 3130 durometer (Germany) according to the ISO 7619-1 standard. The rebound resilience was determined with a Schob type pendulum (Italy) in accordance with the ISO 4662 standard. Dynamic mechanical properties were assessed with a TA Instruments DMA Q800 analyzer (USA). Samples of dimensions $40 \times 10 \times 2 \mathrm{~mm}$ were subjected to sinusoidal oscillating deformation in the single cantilever bending mode at the frequency of $1 \mathrm{~Hz}$ under the temperature rising rate of $4{ }^{\circ} \mathrm{C} / \mathrm{min}$ within the temperature range between 80 and $40{ }^{\circ} \mathrm{C}$. The morphology of the surfaces of broken samples, after tensile test at the speed of $500 \mathrm{~mm} / \mathrm{min}$, was evaluated using a LEO scanning electron microscope (model 1430 VP, England). The samples were coated with a thin gold layer prior to evaluation.

\section{Results and discussion}

\section{Swelling degree}

The equilibrium swelling degree results are presented in Table 3. Swelling degree increased with GTR content in butyl vulcanizates, which was due to low cross-linking of butyl rubber matrix (migration of curing system is described under "cure characteristics" section) and lowering of cross-linking density of GTR arising from partial devulcanization of GTR. Tetramethylthiuram disulfide accelerator (TMTD) was used as vulcanization accelerator which might have acted as a devulcanization agent for GTR [36-
38]. According to the published data, increasing time of mixing of GTR with a different range of TMTD accelerator content $(1,5-3,25 \mathrm{~g})$ was due to higher concentration of sol fraction, lower cross-linking density and Mooney viscosity of the obtained reclaimed rubber.

Cure characteristics

The influence of GTR content on the specification of the vulcanization process is presented in Fig. 1, Fig. 2, Fig. 3, Fig. 4. Figure 1 shows the effect of GTR content on the vulcanization process of obtained butyl rubber compounds. It was observed that there is an increase in minimum torque and lowered optimal time of vulcanization with the increasing GTR content. The higher GTR content in butyl rubber compounds led to increased level in minimum torque at the rheological curves and lower level of maximum torque, as demonstrated in Fig. 2. The enhanced torque values confirm that the processing of butyl rubber compounds characterized by higher amount of GTR filler becomes harder. The minimal torque level increased due to the crosslinked structure of GTR which hindered its blending with the butyl rubber matrix since higher levels of GTR caused a diminished flow. This has also been confirmed by the increased values of incremental moment, which is a difference between the maximum and minimum torque [39]. Moreover, GTR aggregates with a complex structure, give rise to the formation of free spaces in the rubber matrix which results in increased viscosity of the blends [40]. A lower maximum torque depicted at rheological curves, and decreased scorch time $\left(t_{2}\right)$ shown in Fig. 3 are caused by the migration of sulfur from the butyl rubber matrix into GTR

Table 3 The equilibrium swelling degree of GTR and vulcanizates B0, B1, B3, B5, B7 and B9

\begin{tabular}{llllllllllll}
\hline Property & \multicolumn{1}{l}{ Sample } & \multicolumn{1}{l}{ B } & B1 & B2 & B3 & B4 & B5 & B6 & B7 & B8 & B9 \\
\cline { 2 - 10 } Q (after 144 h) & 1.37 & 2.17 & 2.32 & 2.47 & 2.60 & 2.69 & 2.90 & 2.91 & 3.04 & 3.23 & 3.03 \\
\hline
\end{tabular}




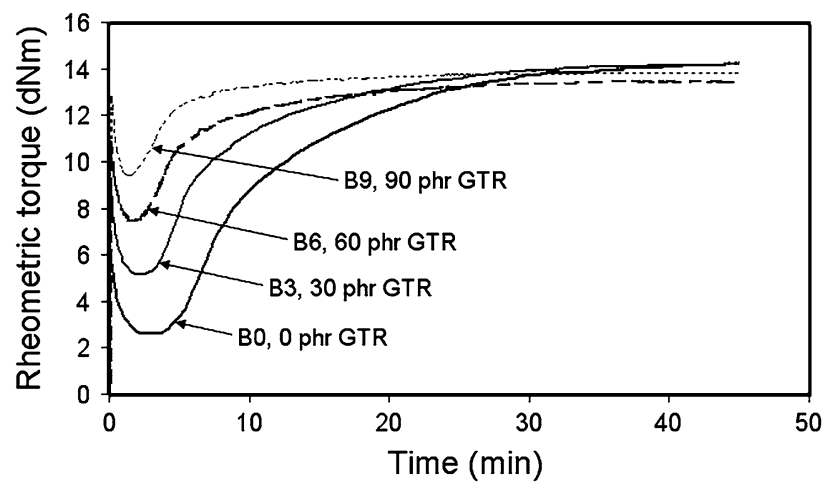

Fig. 1 Cure curves for different ratios of GTR to butyl rubber

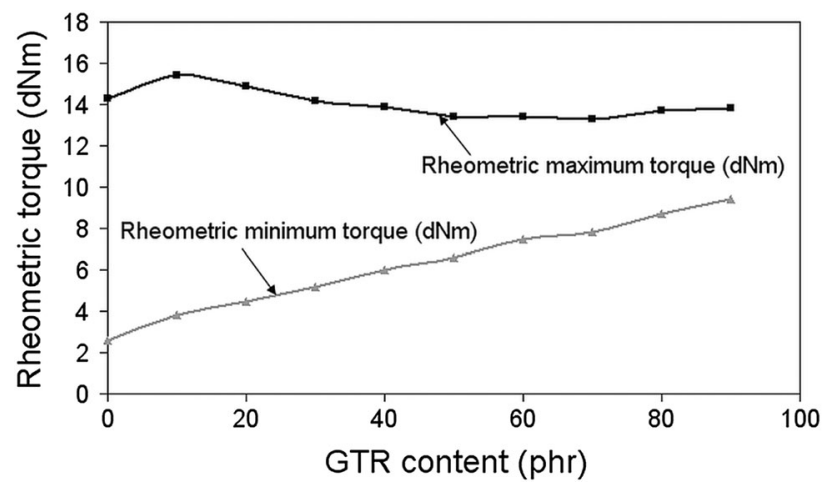

Fig. 2 Effect of GTR on the maximum and minimum rheometric torques at $160{ }^{\circ} \mathrm{C}$

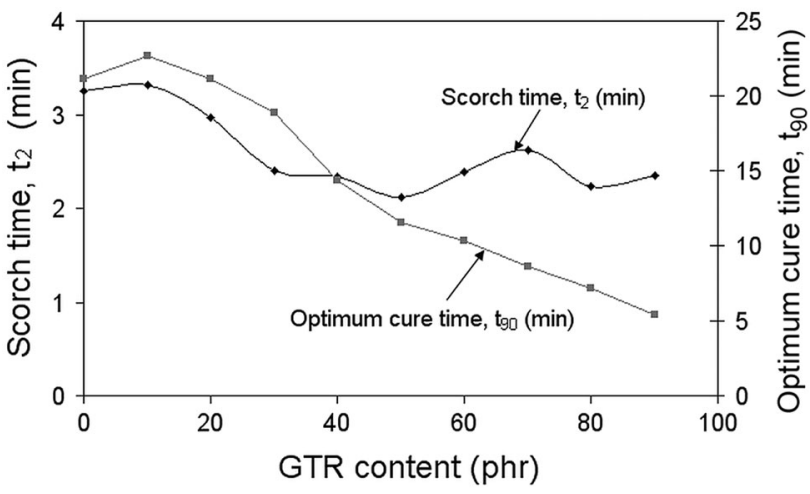

Fig. 3 Effect of ground tire rubber content on the scorch time and optimum cure time

as well as by the migration of accelerators from the GTR matrix into the butyl rubber matrix [41-43]. The observed changes in scorch time can result from different compositions of GTR obtained from whole used tires. The migration of accelerators has been confirmed by reduction in optimal time of vulcanization $\left(t_{90}\right)$, which is shown in Fig. 3. The increasing amount of GTR in rubber compound resulted in lower $t_{90}$. The cure rate index (CRI) [44], which allowed

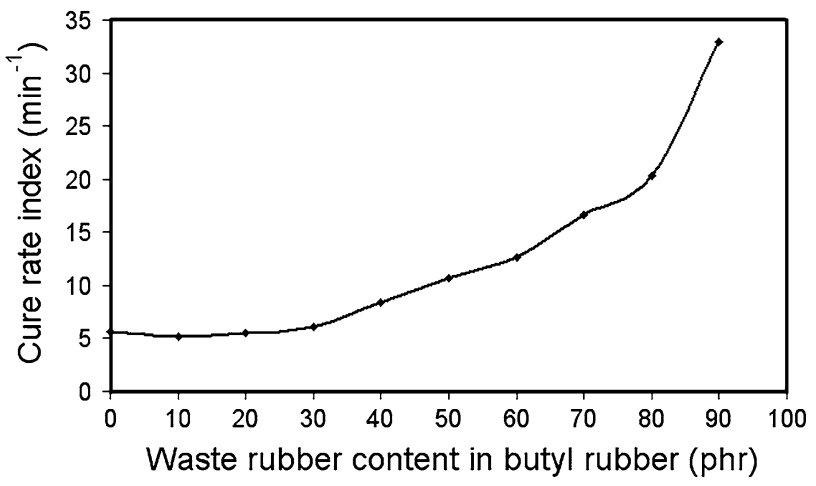

Fig. 4 Cure rate index vs. waste rubber content in the butyl rubber matrix

Table 4 Equilibrium swelling degree and sol fraction of ground tire rubber/butyl rubber blends

\begin{tabular}{lccccc}
\hline Property & \multicolumn{6}{c}{ Butyl rubber content (wt \%) } \\
\cline { 2 - 6 } & 10 & 20 & 30 & 40 & 50 \\
\hline Q (after 72 h) & 1.60 & 1.37 & 1.24 & 1.04 & 0.81 \\
Sol fraction (\%) & 19.1 & 29.2 & 38.1 & 47.6 & 57.3 \\
\hline
\end{tabular}

cross-linking rate determination, was calculated according to the following formula:

$\mathrm{CRI}=\frac{100}{t_{90}-t_{2}}$

A significant increase of CRI, as depicted in Fig. 4, may be explained by the increasing number of unsaturated bonds and higher content of accelerators which are present in the butyl rubber/GTR compounds. The phenomenon may be explained by the competition for the cross-linking agents between unsaturated rubber and the GRT matrix, which results in lowered vulcanization rate [26]. To clarify these assumptions, the curing characteristics of GTR-filled SBR were studied. The SBR compounds were cured under the same conditions of butyl rubber vulcanizates. The results are shown in Table 4. The effect of the type of elastomer and of GTR content on the vulcanization process was noticeable. The obtained compounds are characterized by similar scorch time, which suggests similar mechanism of curing system migration between elastomeric matrix and GTR filler. Optimal vulcanization time for samples based on SBR filled with GTR was much shorter (range 4-7 min) than for vulcanizates based on butyl rubber (range 11-22 min). This is due to different degrees of unsaturation of butyl rubber and SBR. For both types of elastomers, scorch time and optimal time of vulcanization decrease with increasing amount of GTR. Compared to butyl rubber vulcanizates, the use of SBR resulted in 


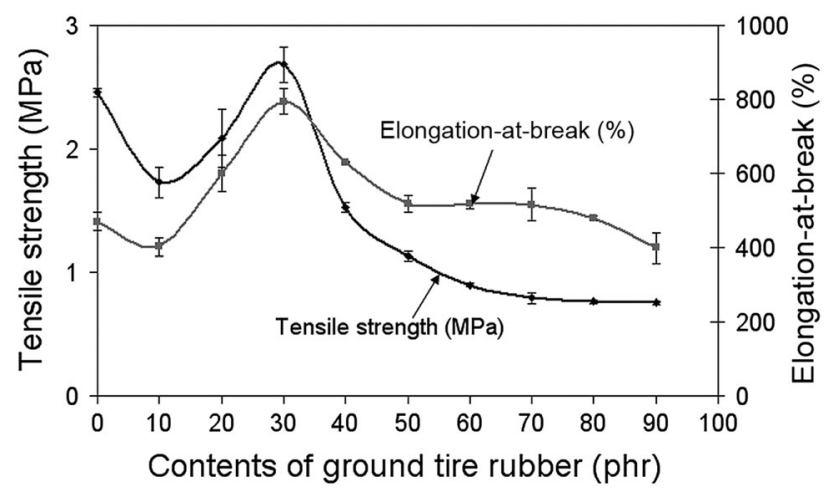

Fig. 5 Effect of GTR on tensile strength (MPa) and elongation-atbreak $(\%)$

increased values of moment increment in relation to crosslink density of the obtained vulcanizates [39].

\section{Mechanical properties}

Tensile strength and elongation-at-break values determined for the samples of vulcanizates are presented in Fig. 5. It was found that the addition of the GTR filler of $10 \mathrm{phr}$ decreased tensile parameters (depicted by the curve minima). Increased level of filler in the vulcanizates (up to $30 \mathrm{phr}$ GTR) affected both tensile strength and elongationat-break in the most positive way (depicted by the curve maxima). A further increase of GTR content in the vulcanizates resulted in lower tensile strength which dropped below the values measured in the reference sample B0 (without filler). Also, elongation-at-break decreased, however, the values of this parameter were higher than those measured for the reference sample B0 (without filler). Higher values in tensile strength and elongation-at-break might have been caused by the carbon black migration from GTR into the butyl rubber matrix. To confirm these assumptions, GTR with different amounts of butyl rubber was blended in the range of $10-50 \mathrm{wt} \%$ using a two-roll mill. Obtained blends were swollen in toluene (methodology described in experimental section). The samples were placed in empty tea bags and immersed in toluene. The uncured components were dissolved and estimated as the sol fraction. Some amounts of carbon black migrated through walls of perforated tea bags into the sol fraction. Table 4 presents equilibrium swelling degree and sol fraction content of blends obtained from GTR with different amounts of butyl rubber. The swelling degree decreases and sol fraction increases with increasing amount of butyl rubber due to solubility of butyl rubber in toluene. In Fig. 6 the photos of a sol fraction residue remaining after the equilibrium swelling are shown. For the butyl rubber content above $10 \mathrm{wt} \%$, particles of carbon black were noticed in the residue after the toluene extraction, which confirmed migration of the active filler from GTR to the butyl rubber matrix. The extracted filler settled to the bottom of the weighing dish and inside the casing in which swelling measurements were conducted. This caused problems during the quantitative analysis of extracted carbon black. In the studied case, the migration mechanism of carbon black ( $\left.\delta=24-30 \mathrm{MPa}^{1 / 2}[45]\right)$ was induced by the shear forces during compounding, similarly as explained by Fenouillot et al. [46]. Filler particles (GTR and carbon black contained therein) and the droplets of the dispersed rubber phase are moving into the butyl rubber matrix so that collisions occur between filler particles (especially fine particles of carbon black) and butyl rubber droplets.

The butyl rubber vulcanizates containing $50-80 \mathrm{phr}$ of GTR revealed similar values of elongation-at-break, while the vulcanizates containing $90 \mathrm{phr}$ of GTR displayed a decreasing trend in this parameter. The values of modules for the obtained vulcanizates at elongation of 100 and $300 \%$ are presented in Fig. 7. The influence of the GTR content on modulus at $100 \%$ elongation was negligible, while for modulus at $300 \%$ elongation a noticeable decrease was observed with increasing GTR content. The optimal tensile properties achieved by vulcanizate B3, which contained $30 \mathrm{phr}$ of GTR, can be explained by the optimal ratio of the number of double bonds to the amount of cross-linking agents in the rubber compound. The number of unsaturated bonds should increase with increasing GTR content in the studied rubber compounds. The unsaturated bonds present in GTR have ability to secondary cross-linking and they were competing with the unsaturated bonds in the butyl rubber matrix. This phenomenon could support a hypothesis on decrease of mechanical properties of the compounds, i.e., tensile strength and modulus, caused rather by the reduced cross-link density of the rubber matrix, than by low adhesion between the matrix and GTR [21]. The effect of the GTR content on hardness and rebound resilience of the studied vulcanizates is presented in Fig. 8. The amounts of GTR did not significantly influence the hardness of the obtained butyl vulcanizates. Small differences measured for sample B4 were most likely caused by the varying composition of GTR which had been obtained from whole used tires. A significant effect of the GTR content on rebound resilience was observed. Rebound resilience values increased linearly with increasing amount of GTR up to $90 \mathrm{phr}$.

The effects of the type of elastomer and GTR content on the mechanical properties are presented in Table 5. Tensile properties of obtained butyl vulcanizates have maximum values for vulcanizate containing $30 \mathrm{phr}$ GTR. For SBR vulcanizates, a partial decrease in tensile properties was observed for vulcanizates containing 10 and $30 \mathrm{phr}$ GTR. Maximum values of tensile properties were exhibited by sample S5 filled with $50 \mathrm{phr}$ of GTR. The obtained results are similar to sample S0 without GTR as filler. The 


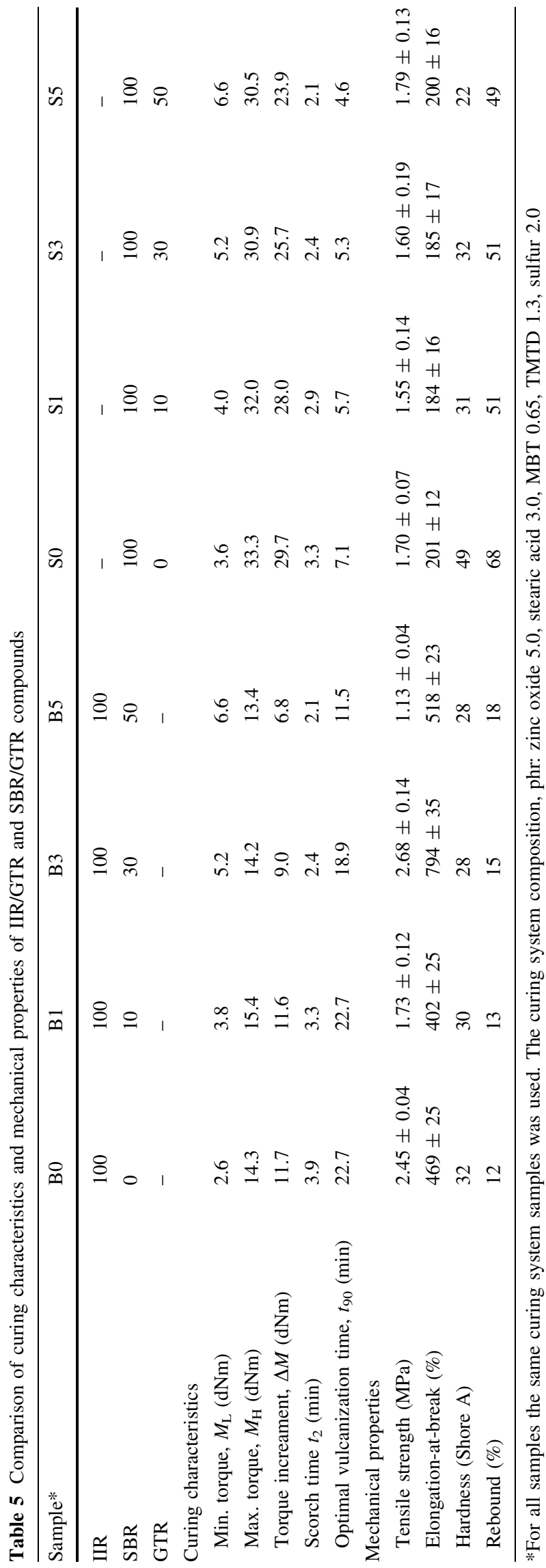

contents of GTR have a negligible influence on hardness of butyl rubber vulcanizates. Hardness of samples based on SBR decreased with higher GTR content, which may have been the result of partially devulcanized GTR by TMTD accelerator. Devulcanization process generated gases (i.e., carbon dioxide) which might have acted like a foaming agent. Rebound resilience of the studied compounds increased slightly for butyl rubber vulcanizates and decreased for SBR vulcanizates, which confirmed the partial devulcanization of GTR by TMTD accelerator.

Dynamic mechanical analysis

In Fig. 9, the relationships between the amount of GTR and both storage modulus and loss modulus are shown. Storage modulus is decreased with increasing GTR content as a result of the devulcanization of GTR structure and slightly cross-linking of butyl rubber matrix, which results in vulcanizates with lower stiffness. The data of swelling degree, presented in Table 3, confirm these results. It was observed that the peak of loss modulus has shifted towards lower temperatures in response to other elastomers (natural rubber, butadiene rubber and SBR) presence in GTR. Moreover, lowered maximum values of loss modulus were caused by increasing contribution of carbon black which is one of the basic GTR components characterized by a very small loss angle [47]. The effect of the GTR content on the relationship between loss tangent and temperature is depicted in Fig. 10. Two maxima were observed within the peak area of the loss tangent curve; however, they are not an indication of different relaxation processes as the relationship of loss modulus vs. temperature is unequivocally defined by one peak only. Relaxations $\beta$ of side chains have been reported by other authors [48] in the case of pure butyl rubber; however, such phenomenon was not enough visible in the compounds investigated in this study. The observed split of the loss tangent peak should be attributed to overlapping effects of the samples' physical heterogeneity and the measuring conditions.

\section{Morphology}

The surface morphology of vulcanizates B1, B3 and B5, which had been subjected to tensile test at the rate of $500 \mathrm{~mm} / \mathrm{min}$, is presented in Fig. 11. A noticeable influence was observed on the amount of GTR used in the vulcanizates with respect to the interactions between GTR and the butyl rubber matrix. The morphology of sample B1, containing $10 \mathrm{phr}$ of GTR, showed a visible lack of adhesion between the GTR particles and butyl rubber matrix (photos $b$ and $c$ of sample B1). Pronounced cohesion cracks in the matrix (photo $\mathrm{c}$ of sample B3) were indications of increased interactions between the butyl rubber matrix and GTR. The 


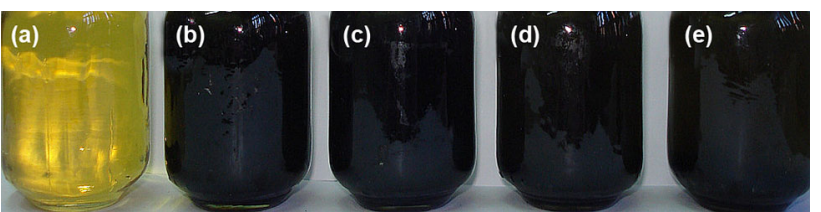

Fig. 6 The influence of butyl rubber content on residue after determining the degree of swelling and the sol fraction content in ground tire rubber. Tested contents of butyl rubber: a 10, b 20, c 30, d 40 and e $50 \mathrm{wt} \%$

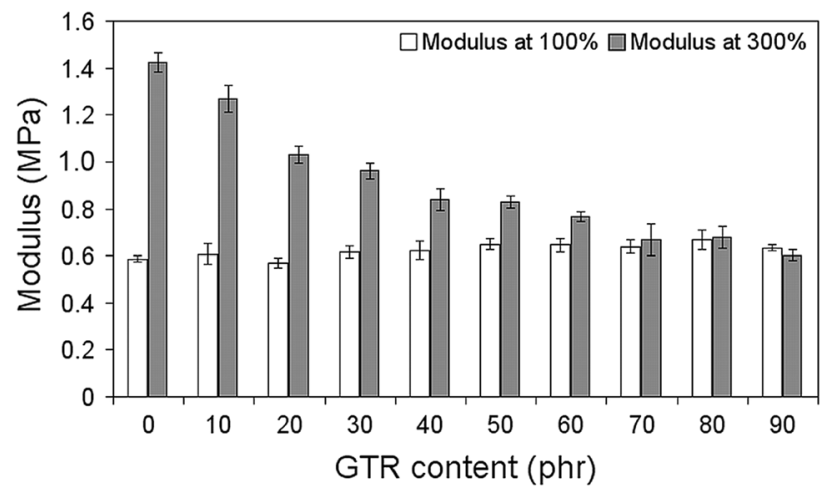

Fig. 7 Effect of GTR content on modulus at 100 and $300 \%$ elongation in the butyl rubber vulcanizate

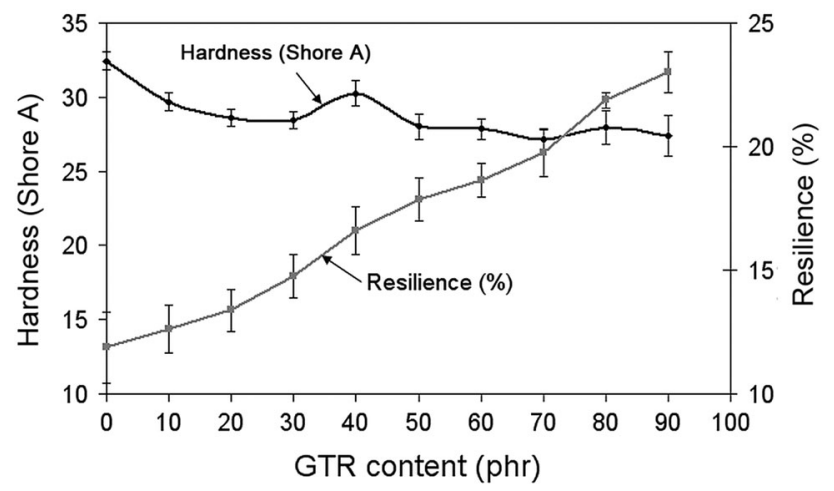

Fig. 8 Effect of GTR content on hardness and resilience of the butyl rubber vulcanizate

presented pictures confirm the results of measurements of static and dynamic mechanical properties conducted for the obtained vulcanizates. The morphology of sample B5, containing $50 \mathrm{phr}$ of GTR, demonstrates the nature of filler/ matrix interactions as documented by the interfacial break resulting from the action of cohesive and adhesive forces (photo c of sample B5).

\section{Conclusion}

The results show that butyl rubber vulcanizates containing $30 \mathrm{phr}$ of GTR as filler were characterized by the highest
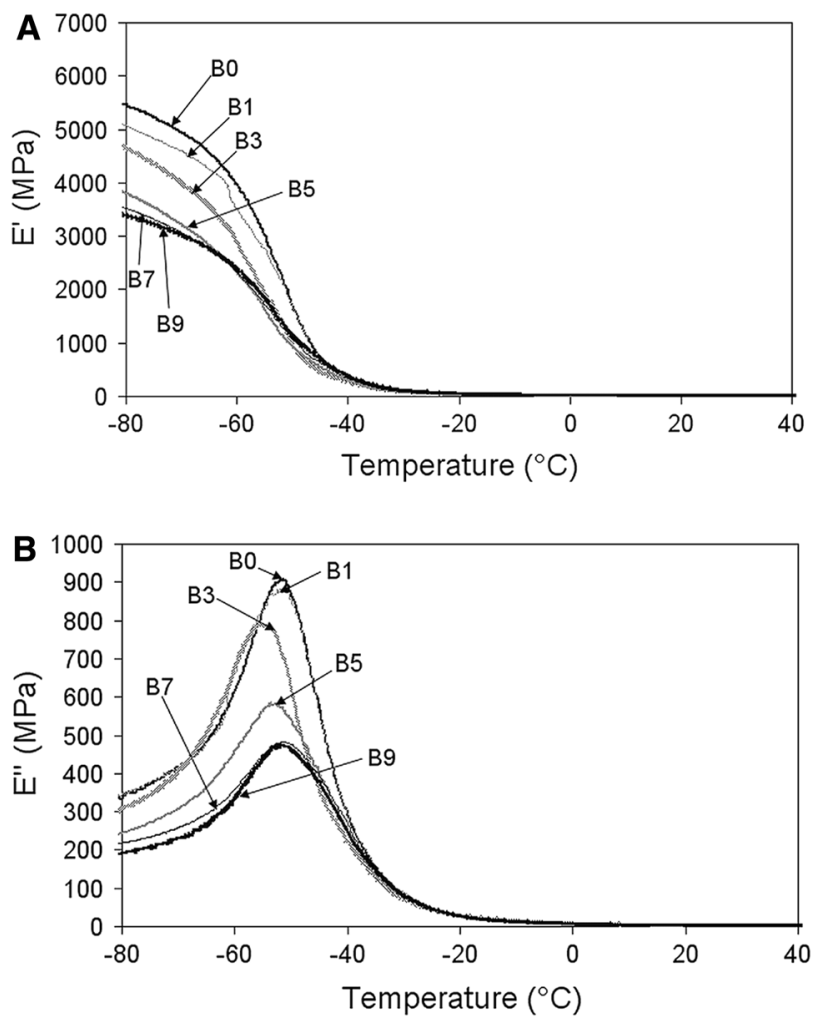

Fig. 9 Effect of ground tire rubber on a storage modulus and $\mathbf{b}$ loss modulus in vulcanizates B0, B1, B3, B5, B7 and B9

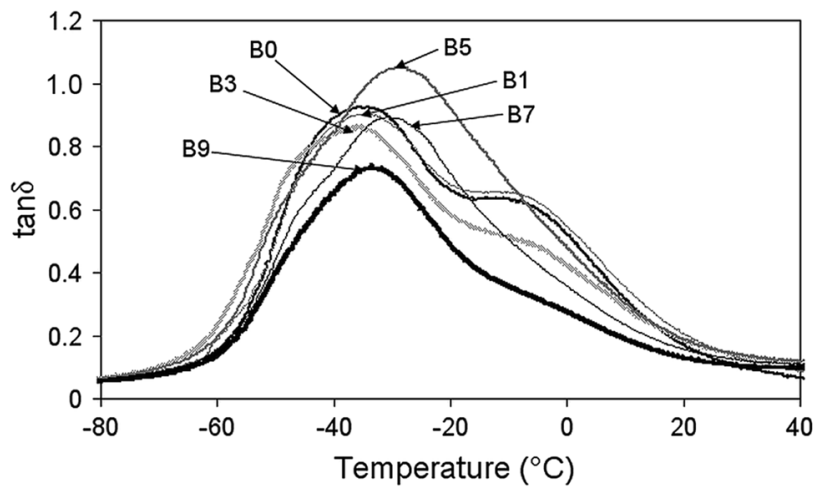

Fig. 10 Effect of ground tire rubber on tangent delta in vulcanizates $\mathrm{B} 0, \mathrm{~B} 1, \mathrm{~B} 3, \mathrm{~B} 5, \mathrm{~B} 7$ and B9

tensile strength (2.68 MPa) and elongation-at-break (794 \%). The optimal properties of the butyl rubber vulcanizates (GTR content of $30 \mathrm{phr}$ ) resulted from the interaction between two factors. First, with the increasing amount of GTR in the butyl rubber compounds, the number of unsaturated bonds increased. Unsaturated bonds of GTR, with possibility to secondary cross-linking, competed with the unsaturated bonds present in the butyl rubber matrix, which decreased mechanical properties, i.e., lowering the tensile strength and modulus. This assumption was confirmed by characteristics of vulcanization process and 
Fig. 11 SEM images of samples B1, B3 and B5
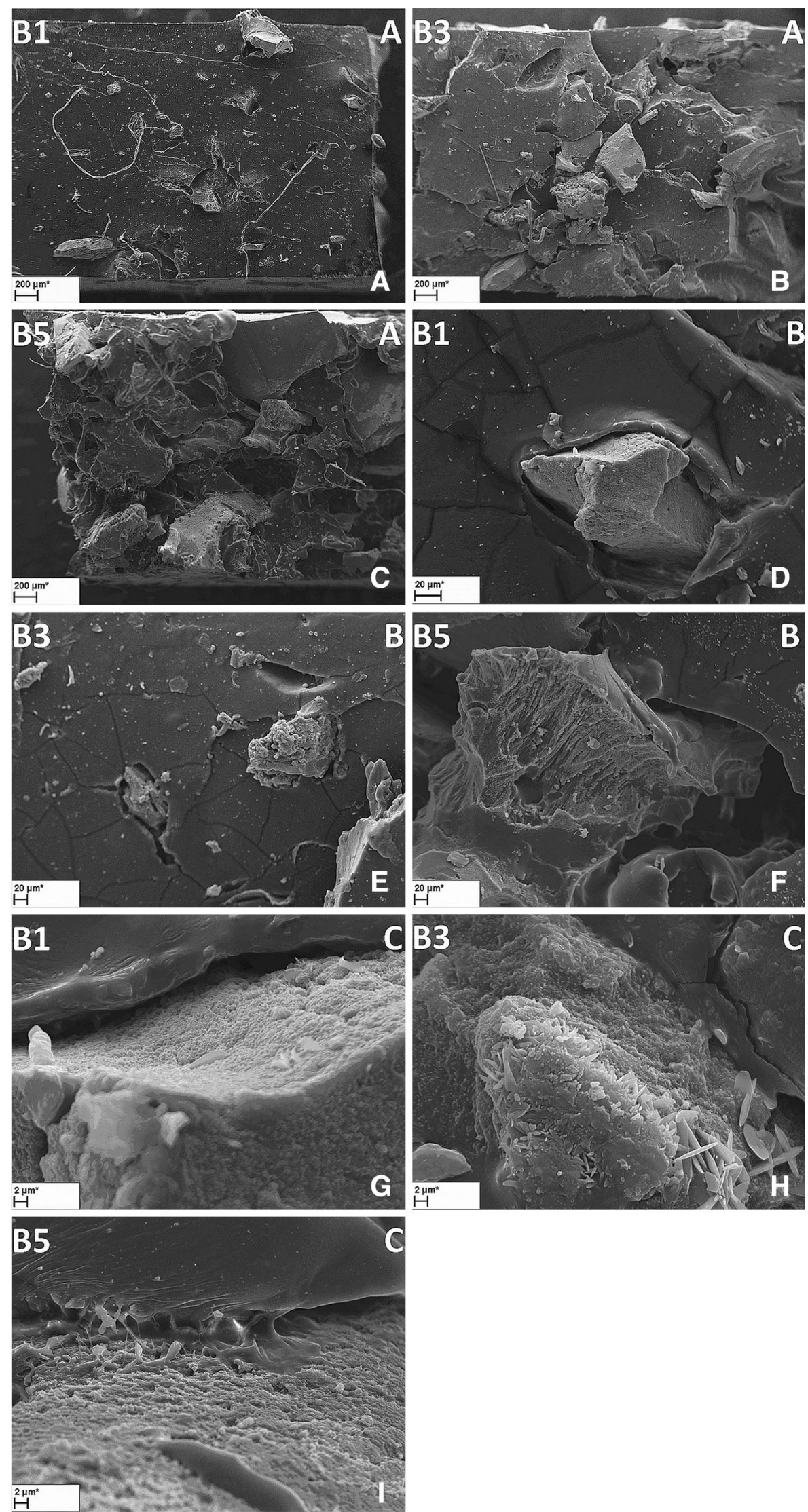

$c$

.


mechanical properties of analogues compositions of SBR vulcanizates obtained under the same conditions. Secondly, the partial migration of active filler, in the form of carbon black, from GTR into the butyl rubber matrix played a significant role. This phenomenon visibly increased elongation-at-break values of the obtained vulcanizates. The microstructure analysis of samples performed after tensile tests showed that in the case of sample B3, containing $30 \mathrm{phr}$ of GTR, there was a strong interaction between the butyl rubber matrix and GTR. The obtained results demonstrated that GTR can be successfully used as nonexpensive filler in butyl rubber-based compounds.

Acknowledgments The work was performed within the framework of the RX-03/46/2011 R\&D project funded by WFOŚiGW (Voivodship Fund for Environmental Protection and Water Management) in Gdansk

Open Access This article is distributed under the terms of the Creative Commons Attribution License which permits any use, distribution, and reproduction in any medium, provided the original author(s) and the source are credited.

\section{References}

1. Karger-Kocsis J, Mészáros L, Bárány T (2013) Ground tyre rubber (GTR) in thermoplastics, thermosets, and rubbers. J Mater Sci 48:1-38

2. Chaubey T, Arastoopour H (2011) Studying the pulverization mechanism of rubber with a modified design of the solid-state shear extrusion process. J Appl Polym Sci 119:1075-1083

3. Pang S (2003) Process for producing fine rubber powder by using waste rubber. US Patent 6,664,304

4. Ucar S, Karagoz S, Ozkan AR, Yanik J (2005) Evaluation of two different scrap tires as hydrocarbon source by pyrolysis. Fuel 84:1884-1892

5. de Marco Rodriguez I, Laresgoiti MF, Cabrero MA, Torres A, Chomo'n MJ, Caballero B (2001) Pyrolysis of scrap tyres. Fuel Process Technol 72:9-22

6. Adhikari B, De D, Maiti S (2000) Reclamation and recycling of waste rubber. Prog Polym Sci 25:909-948

7. Rajan VV, Dierkes KW, Joseph R, Noordermeer JWN (2006) Science and technology of rubber reclamation with special attention to NR-based waste latex products. Prog Polym Sci 31:811-834

8. Sonnier R, Leroy E, Clerc L, Bergeret A, Lopez-Cuesta JM, Bretelle AS, Ienny P (2008) Compatibilizing thermoplastic/ ground tyre rubber powder blends: efficiency and limits. Polym Test 27:901-907

9. Colom X, Cañavate J, Carrillo F, Suñol JJ (2009) Effect of the particle size and acid pretreatments on compatibility and properties of recycled HDPE plastic bottles filled with ground tyre powder. J Appl Polym Sci 112:1882-1890

10. Scaffaro R, Tzankova Dintcheva N, Nocilla MA, La Mantia FP (2005) Formulation, characterization and optimization of the processing condition of blends of recycled polyethylene and ground tyre rubber: mechanical and rheological analysis. Polym Degrad Stabil 90:281-287

11. Formela K, Stankiewicz P, Kołacka K, Piszczyk Ł, Haponiuk J (2012) The effect of processing parameters and devulcanization conditions on compatibility and properties of LDPE/ground tire rubber compositions. Przem Chem 91:1762-1766

12. Tan K, Chunxi L, Meng H, Wang Z (2009) Preparation and characterization of thermoplastic elastomer of poly(vinyl chloride) and chlorinated waste rubber. Polym Test 28:2-7

13. Satapathy S, Nag A, Nando GB (2010) Thermoplastic elastomers from waste polyethylene and reclaim rubber blends and their composites with fly ash. Process Saf Environ Protect 88:131-141

14. Naskar AK, De SK, Bhowmick AK (2002) Thermoplastic elastomeric composition based on maleic anhydride-grafted ground rubber tire. J Appl Polym Sci 84:370-378

15. Nevatia P, Banerjee TS, Dutta B, Jha A, Naskar AK, Bhowmick AK (2002) Thermoplastic elastomers from reclaimed rubber and waste plastics. J Appl Polym Sci 83:2035-2042

16. Navarro FJ, Partal P, Martinez-Boza FJ, Gallegos C (2010) Novel recycled polyethylene/ground tire rubber/bitumen blends for use in roofing applications: thermomechanical properties. Polym Test 29:588-595

17. Xiao F, Amirkhanian SN (2010) Laboratory investigation of utilizing high percentage of RAP in rubberized asphalt mixture. Mater Struct 43:223-233

18. Mortazavi SB, Rasoulzadeh Y, Yousefi AA, Khavanin A (2010) Properties of modified bitumen obtained from vacuum bottom by adding recycled waste polymers and natural bitumen. Iran Polym J 19:197-205

19. Sukontasukkul $P$ (2009) Use of crumb rubber to improve thermal and sound properties of pre-cast concrete panel. Construct Build Mater 23:1084-1092

20. Li S, Lamminmäki J, Hanhi K (2005) Effect of ground rubber powder and devulcanizates on the properties of natural rubber compounds. J Appl Polym Sci 97:208-217

21. Kim SW, Hong KH, Seo KH (2003) Effects of ground rubber having different curing systems on the crosslink structures and physical properties of NR vulcanizates. Mater Res Innov 7:149-154

22. Ismail H, Nordin R, Noor AM (2003) The effects of recycle rubber powder (RRP) content and various vulcanization systems on curing characteristics and mechanical properties of natural rubber/RRP blends. Iran Polym J 12:373-380

23. Han SC, Han MH (2002) Fracture behavior of NR and SBR vulcanizates filled with ground rubber having uniform particle size. J Appl Polym Sci 85:2491-2500

24. Formela K, Kołacka K, Stankiewicz P, Haponiuk J, Stasiek A (2012) The effect of carbon black total content on properties of SBR/devulcanizate rubber blends. Przem Chem 91:1767-1769

25. Ismail H, Omar NF, Othman N (2011) Effect of carbon black loading on curing characteristics and mechanical properties of waste tyre dust/carbon black hybrid filler filled natural rubber compounds. J Appl Polym Sci 121:1143-1150

26. Carli LN, Boniatii R, Teixeira CE, Nunes RCR, Crespo JS (2009) Development and characterization of composites with ground elastomeric vulcanized scraps as filler. Mater Sci Eng C 29:383-386

27. Carli LN, Bianchi O, Mauler RS, Crespo JS (2011) Crosslinking kinetics of SBR composites containing vulcanized ground scraps as filler. Polym Bull 67:1621-1631

28. Zhang X, Lu C, Liang M (2009) Properties of natural rubber vulcanizates containing mechanochemically devulcanized ground tire rubber. J Polym Res 16:411-419

29. Yehia AA, Mull MA, Ismail MN, Hefny YA, Abel-Bary EM (2004) Effect of chemically modified waste rubber powder as a filler in natural rubber vulcanizates. J Appl Polym Sci 93:30-36

30. Lee SH, Hwang SH, Kontopoulou M, Sridhar V, Zhang ZX, Xu D, Kim JK (2009) The effect of physical treatments of waste rubber powder on the mechanical properties of the revulcanizate. J Appl Polym Sci 112:3048-3056 
31. Baeta DA, Zattera JA, Oliveira MG, Oliveira PJ (2009) The use of styrene-butadiene rubber waste as a potential filler in nitrile rubber: order of addition and size of waste particles. Braz J Chem Eng 26:23-31

32. Zhang X, Zhu X, Liang M, Lu C (2009) Improvement of the properties of ground tire rubber (GTR)-filled nitrile rubber vulcanizates through plasma surface modification of GTR powder. J Appl Polym Sci 114:1118-1125

33. Feng WL, Isayev A (2005) Blends of ultrasonically devulcanized tire-curing bladder and butyl rubber. J Mater Sci 40:2883-2889

34. Deanin RD, Hashemiolya SM (1987) Polyblends of reclaimed rubber with eleven thermoplastics. Polym Mater Sci Eng 57:212-216

35. Brandrup J, Immergut EH, Grulke EA (1999) Polymer handbook, 4th edn. Wiley, New York

36. De D, Das A, De D, Dey B, Debnath SC, Roy BC (2006) Reclaiming of ground rubber tire (GRT) by a novel reclaiming agent. Eur Polym J 42:917-927

37. De D, Singharoy GM (2007) Reclaiming of ground rubber tire by a novel reclaiming agent. I. Virgin natural rubber/reclaimed GRT vulcanizates. Polym Eng Sci 47:1091-1100

38. De D, De D (2011) Processing and material characteristics of a reclaimed ground rubber tire reinforced styrene butadiene rubber. Mater Sci Appl 2:486-495

39. Kim SW, Park HY, Lim JC, Jeon IR, Seo KH (2007) Cure characteristics and physical properties of ground-rubber-filled natural rubber vulcanizates: effects of the curing systems of the ground rubber and rubber matrix. J Appl Polym Sci 105:2396-2406
40. Li S, Lamminmäki J, Hanhi K (2005) Improvement of mechanical properties of rubber compounds using waste rubber/virgin rubber. Polym Eng Sci 45:1239-1246

41. Gibala D, Hamed GR (1994) Cure and mechanical behavior of rubber compounds containing ground vulcanizates. Part I: cure behavior. Rubber Chem Technol 67:636-648

42. Gibala D, Laohapisitpanich K, Thomas D, Hamed GR (1996) Cure and mechanical behavior of rubber compounds containing ground vulcanizates. Part II: Mooney viscosity. Rubber Chem Technol 69:115-119

43. Gibala D, Thomas D, Hamed GR (1999) Cure and mechanical behavior of rubber compounds containing ground vulcanizates. Part III. Tensile and tear strength. Rubber Chem Technol 72:357-360

44. Menon ARR, Pillai CKS, Nando GB (1998) Vulcanization of natural rubber modified with cashew nut shell liquid and its phosphorylated derivative-a comparative study. Polymer 39:4033-4036

45. Grossman RF (1997) The mixing of rubber. Chapman \& Hall, London

46. Fenouillot F, Cassagnau P, Majesté JC (2009) Uneven distribution of nanoparticles in immiscible fluids: morphology development in polymer blends. Polymer 50:1333-1350

47. Smit PPA (1966) The glass transition in carbon black reinforced rubber. Rheol Acta 5:277-283

48. Wu J, Huang G, Pan Q, Zheng J, Zhu Y, Wang B (2007) An investigation on the molecular mobility through the glass transition of chlorinated butyl rubber. Polymer 48:7653-7659 